\title{
EDITORIAL:
}

\section{SOFTWARE SURVEY SECTION}

The introduction of the new Software Section to INSECT SCIENCE AND ITS APPLICATION is to encourage the open exchange of information on software programs unique to our professional field. With the rapid penetration of computers into academic and industrial institutions has come a rarallel increase in the number of scientists and reseurchers designing their own software. The existence of much of this software remains unknown even to those of us who could most benefit from its use. We believe that it is of vital importance to our readers that such information be made available. We also believe that a professional journal is the best place to share such information. Your contribution would be most welcome. 


\section{Journal: INSECT SCIENCE AND ITS APPLICATION}

Please complete the form and send it to the Editor-in-Chief, Professor Thomas R. Odhiambo, Insect Science and Its Application, P.0. Box 72913, Nairobi, Kenya, East Africa. The description will be published in the journal without review or comment

Software Package:

Contributor/Address:

Brief Description:

Field of Application:

Potential Users: 


\section{SOFTWARE SURVEY SECTION}

The software description has been provided by our readers and authors to facilitate exchange of information on software programs. The information has not been reviewed. It is being transmitted through the journal to users from the contributor.

You are invited to complete and submit the software description form provided at the end of the section. You may photocopy the form without permission.

Software Package: THE OBSERVER, version 1.31

Contributor/Address: L.P.J.J. Noldus, Department of Entomology, Agricultural University, P.O. Box 8031, 6700 EH Wageningen, The Netherlands

Brief Description: THE OBSERVER is an integrated software package for behavioural research, for the purpose of computer-aided event recording and data analysis. THE OBSERVER creates the software necessary to permit a portable computer to act as an event recorder. The program itself operates on a full-size personal computer. The user tells the program the type of portable computer used, the type of observations planned and what events should be recorded; THE OBSERVER writes the event-recording program and transfers it to the portable computer. The portable computer can then be taken to the experimental set-up or into the field for data collection. The program allows 86 keys to be defined as events. As many as 20 questions related to experimental conditions can be defined; the answers to these are stored with the rest of the data. THE OBSERVER can also retrieve the data files from the portable computer, calculate statistics, and produce reports and tables that can be printed or imported into spreadsheet- or statistical programs. THE OBSERVER requires an IBM PC, PS $/ 2$ or compatible computer, as well as a TRS-80 Model 100, Tandy 102 or Epson PX-8 portable computer.

Field of Application: Computer-aided event recording and data analysis in behavioural research

Potential Users: Anybody whose research involves direct observations of the behaviour of living organisms (entomologists, zoologists, ethologists, etc.) 


\section{SOFTWARE SURVEY SECTION}

The software description has been provided by our readers and authors to facilitate exchange of information on software prograns. The information has not been reviewed. It is being transmitted through the journal to users from the contributor.

You are invited to complete and submit the software description form provided at the end of the section. You may photocopy the form without permission.

Software Package: Lotus $1-2-3$

Contributor/Address: Ashton Tate

Brief Description: Spreadsheet, graphics, database and wordprocessing integrated software

Field of Application:

Potential Users: All staff 